\title{
Short communication: Evaluation of supercritical fluid extraction aids for optimum extraction of nonpolar lipids from buttermilk powder
}

\author{
A. J. Spence, ${ }^{*} \dagger$ R. Jimenez-Flores, $\dagger^{1}$ M. Qian, ${ }^{*}$ and L. Goddik ${ }^{*}$ \\ ${ }^{*}$ Department of Food Science and Technology, Oregon State University, Corvallis 97330 \\ †Dairy Products and Technology Center, California Polytechnic State University, San Luis Obispo 93407
}

\begin{abstract}
The milk fat globule membrane, present in buttermilk, contains complex lipids such as phospholipids. Microfiltration coupled with supercritical fluid extraction (SFE) may provide a method of enriching these nutritionally valuable lipids into a novel ingredient. Therefore, SFE as a method for phospholipid enrichment needs to be optimized for lipid removal effectiveness. The role of matrix additions to the buttermilk powder for extraction efficiency was evaluated. Diatomaceous earth (biosilicates), Teflon beads, and physical vibration were tested and shown to reduce total lipid by 86,78 , and $70 \%$, respectively. Four consecutive treatments were shown to exhaust the system; however, similar extraction efficiencies were noted for 1 treatment with biosilicate addition, 2 treatments with physical vibration, or 3 treatments with added Teflon beads. The extracted lipid material consisted of the nonpolar fraction, and protein concentration was observed to increase slightly compared with the control. Although higher lipid extraction was achieved from the powder with addition of diatomaceous earth, a removable aid is ideal for an edible product.
\end{abstract}

Key words: supercritical fluid extraction, milk fat globule membrane, milk phospholipid, diatomaceous earth

Phospholipids (PL) are associated with both the milk fat and proteins and are largely concentrated in the milk fat globule membrane (MFGM; Warner, 1976; Renner et al., 1989). Phospholipids function as integral components of the membrane and are known to be involved with other biological processes. The major types and their estimated percentages are phosphatidylcholine, $31 \%$; phosphatidylethanolamine, $30.5 \%$; sphingomyelin, $19.9 \%$, phosphatidylinositol, $7.1 \%$; phosphatidylserine, $5 \%$; lactosyl-cerebroside, $3.4 \%$; and glucosyl-cerebroside, $0.3 \%$ (Fong et al., 2007). The approximate ratio of

Received April 9, 2009.

Accepted July 20, 2009.

${ }^{1}$ Corresponding author: rjimenez@calpoly.edu proteins to lipids within the membrane is 1:1 (Kanno, 1990). Glycoproteins are concentrated on the outer surface, whereas other proteins, such as xanthine oxidase, strongly bind lipid material and are located on the inner surface. Other proteins, such as butyrophilin, are transmembrane proteins and are embedded within the membrane (Deeth, 1997; Jensen, 2002). Sphingolipids, in particular, are known to have essential roles in cell survival, growth, and death (Okazaki et al., 1989; Kim et al., 1991; Huwiler et al., 2000; Lightle et al., 2000). Because of its unique composition and concentration of these lipids, MFGM in buttermilk could be used as a source of PL.

Several attempts in fractionating buttermilk components have been made, primarily using filtration processes. Morin et al. (2004) reported on the effects of temperature and pore size in microfiltration of fresh and reconstituted buttermilk. When using a temperature of $25^{\circ} \mathrm{C}$, higher amounts of retained fat coupled with a large amount of protein transmission were observed. Improved separation between lipids and proteins was shown using fresh rather than reconstituted buttermilk. Pore size also affected buttermilk fractionation - both protein and lipid contents were increased in the retentate when using a $0.1-\mu \mathrm{m}$ membrane compared with a $0.8-\mu \mathrm{m}$ and a $1.4-\mu \mathrm{m}$ pore size. Rombaut et al. (2006) showed that using microfiltration and sodium citrate or ethanol addition for the separation of lipids and proteins was not possible. Although micelle dissociation allowed effective transmission of casein through the membrane, high membrane fouling along with PL loss was observed.

Supercritical fluid extraction (SFE) is an additional method utilizing carbon dioxide that can selectively extract lipid components of a complex mixture. A previous study by Astaire et al. (2003) found that the bioactive lipids of the MFGM could be concentrated within reconstituted buttermilk by combining microfiltration and SFE. A cross-flow microfiltration system (0.8- $\mu \mathrm{m}$ pore size) was optimized for cold, reconstituted buttermilk powder (BMP) to first concentrate the lipids. Further treatment using SFE successfully removed nonpolar lipids, specifically triacylglycerides (21 to 4 
mg of lipid/g of dry powder) to increase concentrations of polar MFGM lipid (namely sphingomyelin, phosphatidylcholine, and phosphatidylethanolamine; 9.6 to $19.7 \mathrm{mg}$ of lipid/g of dry powder) in BMP. In previous studies, the addition of biosilicate material, specifically Celite (World Minerals Inc., Lompoc, CA), served to increase efficiency by providing space between the powder particles, enabling better penetration of solvent, and in turn, increasing lipid extraction (Berg et al., 1997; Astaire et al., 2003). However, the addition of biosilicate material leaves the product inedible because of sandiness; therefore, examination of other modifications is needed.

The goal of this project was to investigate SFE extraction aids in relation to lipid extraction efficiency by measuring the effectiveness of lipid removal. Extraction aids such as diatomaceous earth, polytetrafluoroethylene beads, and physical mixing to mimic the fluidized bed were used. Composition (lipid and protein) of the treated powders was assessed.

Fresh regular manufacturing cream was provided by Foster Farms (Modesto, CA). Butter was made using a continuous pilot-scale butter churn (Egli, Switzerland). Recovered buttermilk was filtered and spray dried using a Niro Filterlab Spray Dryer (Hudson, WI) following the manufacturer's instructions. For reconstitution of the dried buttermilk, tap water was added to give a $10 \%$ total solids solution, and the mixture was allowed to sit overnight at $4^{\circ} \mathrm{C}$ to hydrate fully. The microfiltration unit (pore size of $0.45 \mu \mathrm{m}$ ) was an stainless steel shell and tube module manufactured in-house and containing Tami Sunflower Design ceramic membranes (Tami Industries, France) as described earlier (Astaire et al., 2003; Morin et al., 2004). The $0.45-\mu \mathrm{m}$ pore size was chosen to lower the transmission level of lipids and to decrease fouling of the membrane. All runs were carried out at low temperature $\left(8-10^{\circ} \mathrm{C}\right)$ at a transmembrane pressure of 80 to $95 \mathrm{kPa}$, and buttermilk was concentrated to a volumetric concentration factor of $2 \times$. Previous studies have shown that lower and more stable fluxes were observed as well as a more efficient retention of MFGM lipids during cold processing (Astaire et al., 2003; Morin et al., 2004). Final retentates were spray dried using a Niro Filterlab Spray Dryer.

The SFE system and components were acquired from Thar Designs Inc. (Pittsburgh, PA) and were described previously by Astaire et al. (2003). Briefly, the in-house unit included the following: 500-mL vessel, model P-50 high-pressure pump, automated back pressure regulator model BPR-A-200B, and PolyScience (Niles, IL) brand water bath and pump unit (model 9505). Circulated deionized water at $5^{\circ} \mathrm{C}$ was used for cooling different zones in the SFE apparatus. Carbon dioxide tanks $(50 \mathrm{lb}$ ) were filled and inspected by Airgas West
(San Luis Obispo, CA). The system conditions were controlled manually by Windows 2000-based software (Hewlett-Packard, Palo Alto, CA). The running conditions were as follows: pressure, $35 \mathrm{MPa}$; temperature, $50^{\circ} \mathrm{C}$; flow rate, $20 \mathrm{~g} / \mathrm{min}$; total vessel flushes, $3.40 \pm$ 0.51 ; total run time, $94.00 \pm 0.14 \mathrm{~min}$; and total $\mathrm{CO}_{2}$ used, $1,700.0 \pm 226 \mathrm{~g}$. Previous studies have shown an optimized temperature and pressure combination for polar lipid extraction from buttermilk powder at $350^{\circ} \mathrm{C}$ and $5 \mathrm{MPa}$, respectively (Spence et al., 2009). Following treatment, the SFE extraction vessel was rinsed with 50 to $100 \mathrm{~mL}$ of chloroform:methanol $(2: 1 \mathrm{vol} / \mathrm{vol})$ into a preweighed, dried aluminum pan. The solvent was evaporated on a hot plate under a ventilated hood, and the residue lipids were dissolved and diluted to $10 \mathrm{mg} /$ $\mathrm{mL}$ in chloroform-methanol $(2: 1, \mathrm{vol} / \mathrm{vol})$.

For the experimental design, a $2 \times$ microfiltration with volumetric concentration (VCMF) BMP retentate (fat $=17.39 \pm 0.06 \%$ ) was used. Four powder systems were used, as follows: 1) without added Celite 566 or Teflon beads and rings (no addition); 2) with added Celite 566 (50:50 wt/wt; World Minerals Inc.), BIOSIL; 3) with added Teflon (polytetrafluoroethylene) beads and rings (24.2:50 wt/wt), $3 \mathrm{~mm}$ in diameter (\#09-191-30A and 09-191-25A, respectively; Fisher Scientific, Pittsburgh, PA), TB; and 4) with physical mixing (i.e., fluidized bed simulation). Celite 566 is essentially $6 \times 60$ mesh $(3,360 \times 250 \mu \mathrm{m})$, where at least $80 \%$ by weight of the product is within that size range, and the rest of the particles are $<60 \mu \mathrm{m}$. Because of the extreme coarseness of Celite 566, typical laser-based particle size distribution measurements are not meaningful; it is essentially a granular product. To simulate the extraction of SFE coupled with a fluidized bed, the SFE vessel was opened during the run following one vessel flush (500 g of $\mathrm{CO}_{2}$ ), the powder was manually stirred, and the extraction continued. The sample was stirred 3 times in a complete run. Each powder was given a total of 12 stirrings in a $4 \times$ run. The SFE treatments at the specified parameters were performed on each powder, until the percentage fat in the powder remained unchanged. Following SFE treatments, the Teflon beads were removed by sifting the powder, whereas Celite was not removed from the powders. The SFE extractions for all powder systems were carried out in triplicate. Other systems, including different silicates, were not studied in the present experiment because our goal was to obtain an ingestible product with increased phospholipids; therefore, only systems that could be easily removed from the buttermilk powder were examined. The total fat was extracted from the BMP samples in duplicate by the Mojonnier method and analyzed by thin layer chromatography following the procedures detailed below. Lipid extraction efficiency was compared 
between the powder systems. Systems were designated as follows: powder with no additions, BIOSIL, TB, and physical mixing.

Percentage protein was determined by testing for total N content by the Kjeldahl method (AOAC, 1995; method 955.04). Lipid content was determined by using the Mojonnier ether extraction method as described by Marshall (1992).

Graphics, statistics, and experimental design were performed using Minitab 14.0 software (Minitab Inc., State College, PA). All comparisons were done by ANOVA with Tukey's pairwise comparison using Minitab 14.0 software. Results were considered statistically different at $P<0.05$.

Table 1 shows the protein and lipid composition as well as the percentage of lipids removed by the SFE process after 4 treatments. In relation to protein content, significant differences were shown between powders with different additives $(P=0.003)$. Results showed that the BIOSIL powder had a greater amount of protein than the TB powder and the powder with no additives. Similarly, lipid content was different $(P=$ $0.000)$ between the experimental powders, with the BIOSIL powder being lower than the TB and no addition powders. The average percentage total fat removal for SFE treatments with added adsorbent is shown in Figure 1. For all powders, the first SFE treatment greatly reduced lipid content by at least $50 \%$, independently of powder modifications. The SFE process with BIOSIL yielded a greater efficiency of total fat removal (77\%) than that without added biosilicates. An additional SFE treatment reduced the amount of total fat in the powders by an average of 85 and $63 \%$ with and without added biosilicates, respectively. A fourth SFE treatment on the BIOSIL powder had no effect on further fat removal. This is consistent with results of a previous study (Astaire et al., 2003). However, without any aids for extraction, 4 treatments were required to extract the same amount of lipid compared with that obtained in just one treatment when biosilicates were present. The addition of TB resulted in $78 \%$ removal after 3 treatments. Although lipid removal in the powder with beads was less than in the powder with biosilicates, the

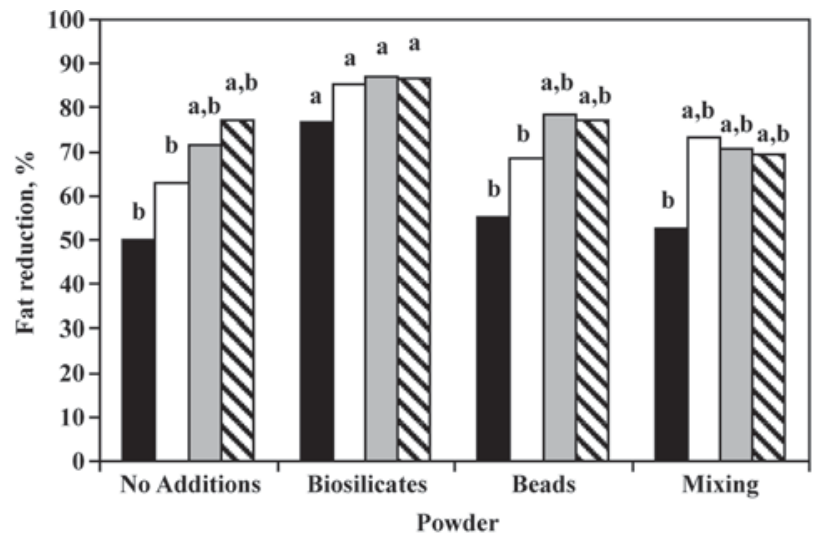

Treatment $1 \quad \square$ Treatment $2 \quad \square$ Treatment $3 \quad \square$ Treatment 4

Figure 1. Average percentage fat removal for supercritical fluid extraction treatments on powder with no additions, added biosilicates, added Teflon beads and rings (beads), or fluidized bed simulation (mixing). ${ }^{\mathrm{a}, \mathrm{b}}$ Bars with different letters denote significant differences $(P<0.05)$. Each bar represents the treatment repetition $(1$ to 4$)$ of extractions at $35 \mathrm{MPa}$ and $50^{\circ} \mathrm{C}$ using $1,683 \pm 226 \mathrm{~g}$ of $\mathrm{CO}_{2}$.

use of TB offers an attractive alternative because beads are removable. Using a bed fluidizer in conjunction with SFE may create a constant flowing space between the powder particles, enabling greater lipid extraction. Mixing of the powder at intervals during the treatment served to simulate a fluidized bed and demonstrated that it may be ideal. According to the data presented in Figure 1, we show that 2 treatments with mixing were equivalent to 3 treatments with TB. We think that constant powder mixing within the SFE sample vessel would increase lipid extraction to a degree comparable to that of adding biosilicates by increasing the surface area within the powder and therefore enabling greater solvent penetration.

Another explanation for the greater efficiency following the first 2 treatments of the BIOSIL powder is component interaction, perhaps lipid or protein material, within the BMP matrix and the biosilicates. It has been previously shown that biosilicate material absorbs specific protein and phospholipids from the MFGM during buttermilk filtration (Fryksdale, 2000). However, stud-

Table 1. Compositional data (mean \pm SD) for buttermilk powder (BMP) undergoing no treatment or after 4 treatments with supercritical fluid extraction and additives or physical mixing

\begin{tabular}{lccc}
\hline BMP & Protein, $\%$ & Lipid, $\%$ & Lipid reduction, $\%$ \\
\hline No treatment & $37.66 \pm 1.02^{\mathrm{a}}$ & $17.39 \pm 0.08^{\mathrm{a}}$ & $\mathrm{NA}^{1}$ \\
No additives & $34.45 \pm 0.66^{\mathrm{a}}$ & $3.98 \pm 0.26^{\mathrm{b}}$ & $65.49 \pm 11.80$ \\
Biosilicate addition & $42.62 \pm 0.39^{\mathrm{b}}$ & $2.32 \pm 0.01^{\mathrm{c}}$ & $83.92 \pm 4.97$ \\
Teflon bead addition & $39.05 \pm 0.03^{\mathrm{a}}$ & $4.00 \pm 0.39^{\mathrm{b}}$ & $69.77 \pm 10.70$ \\
Physical mixing & $38.90 \pm 0.41^{\mathrm{ab}}$ & $3.00 \pm 0.49^{\mathrm{bc}}$ & $66.51 \pm 9.32$ \\
\hline
\end{tabular}

${ }^{\mathrm{a}-\mathrm{c}}$ Means in same column with different superscripts differ significantly $(P<0.05)$.

${ }^{1} \mathrm{NA}=$ not applicable. 
ies are limited to the interactions of dry biosilicate matter with milk powder. An overview of silica by Bergna (1994) describes natural biosilicates and the different moieties that occur at their surfaces. Those that can occur are 1) strained and stable siloxane groups, 2) silanol groups: isolated hydroxyl groups, 3) hydrogen-bonded silanol groups: hydroxyl groups on adjacent surface silicon atoms, 4) silanediols: 2 hydroxyls associated with one silicon atom, 5) silanetriols: 3 hydroxyls associated with one silicon atom, and 6) physically absorbed $\mathrm{H}_{2} \mathrm{O}$ hydrogen to all types of surface hydroxyl groups. Materials can attract and be anchored to the surface of biosilicate material by 3 types of binding forces: hydrogen bonding, hydrophobic interactions, and ionic attractions. Much of the observed whey protein binding can be explained by hydrophobic interactions, when the molecule is attracted to the biosilicate surface by hydrophobic forces. A study by Krisdhasima et al. (1993) compared the differences between milk proteins in relation to their adsorption and elution characteristics from hydrophilic and hydrophobic surfaces. $\alpha$-Lactalbumin, $\beta$-lactoglobulin, and BSA all had a higher affinity for hydrophobic surfaces, whereas $\beta$-casein had a higher affinity for hydrophilic surfaces. Among the globular proteins, $\alpha$-lactalbumin, because of its smaller size, had a much greater affinity for hydrophobic surfaces than did the other proteins.

In conclusion, the BMP products developed by combining microfiltration and SFE are rich in polar lipids and protein. Addition of a physical aid, such as removable Teflon beads, or fluidized bed mixing ensures adequate removal of nonpolar lipids for polar lipid enrichment.

\section{ACKNOWLEDGMENTS}

This work was funded in part by the Eckelman Graduate Assistantship, the California Dairy Research Foundation, and the California State University Agriculture Research Initiative. The authors express gratitude to Pierre Morin, Jessica Yee, Lorna Lassonde, and the Dairy Products Technology Center (California Polytechnic State University, San Luis Obispo) staff.

\section{REFERENCES}

AOAC. 1995. Official Methods of Analysis. 16th ed. Association of Official Analytical Chemists, Gaithersburg, MD.
Astaire, J. C., R. Ward, J. B. German, and R. Jimenez-Flores 2003. Concentration of polar MFGM lipids from buttermilk by microfiltration and supercritical fluid extraction. J. Dairy Sci. 86:2297-2307.

Berg, H., M. Magard, G. Johansson, and L. Mathiasson. 1997. Development of a supercritical fluid extraction method for determination of lipid classes and total fat in meats and its comparison with conventional methods. J. Chromatogr. A 785:345-352.

Bergna, H. 1994. Colloid Chemistry of Silica. Pages 9-36 in The Colloid Chemistry of Silica . H. E. Bergna, ed. Advances in Chemistry Series 234. American Chemical Society, Washington, DC.

Deeth, H. C. 1997. The role of phospholipids in the stability of milk fat globules. Aust. J. Dairy Technol. 52:44-46.

Fong, B. Y., C. S. Norris, and A. K. H. MacGibbon. 2007. Protein and lipid composition of bovine milk-fat-globule membrane. Int. Dairy J. $17: 275-288$.

Fryksdale, B. 2000. Modification of buttermilk functionality by a nove absorption process. Thesis. California Polytechnic State University, San Luis Obispo.

Huwiler, A., T. Kolter, J. Pfeilschifter, and K. Sandhoff. 2000. Review: Physiology and pathophysiology of sphingolipid metabolism and signaling . Biochim. Biophys. Acta 1485:63-99.

Jensen, R. G. 2002. Invited review: The composition of bovine milk lipids: January 1995 to December 2000. J. Dairy Sci. 85:295350.

Kanno, C. 1990. Secretory membranes of the lactating mammary gland. Protoplasma 159:184-208.

Kim, M.-Y., C. Linardic, L. Obeid, and Y. Hannun. 1991. Identification of sphingomyelin turnover as an effector mechanism for the action of tumor necrosis factor alpha and gamma-interferon. J. Biol. Chem. 266:484-489.

Krisdhasima, V., P. Vinaraphong, and J. McGuirre. 1993. Adsorption kinetics and elutability of $\alpha$-lactalbumin, $\beta$-casein, $\beta$-lactoglobulin, and bovine serum albumin at hydrophobic and hydrophilic interfaces. J. Colloid Interface Sci. 161:325-334.

Lightle, S. A., J. I. Oakley, and M. N. Nikolova-Karakashian. 2000. Activation of sphingolipid turnover and chronic generation of ceramide and sphingosine in liver during aging. Mech. Ageing Dev. 120:111-125.

Marshall, R. T. 1992. Standard Methods for the Examination of Dairy Products. 16th ed. Am. Publ. Health Assoc. Inc., Washington, DC.

Morin, P., R. Jimenez-Flores, and Y. Pouliot. 2004. Effect of temperature and pore size on the fractionation of fresh and reconstituted buttermilk by microfiltration. J. Dairy Sci. 87:267-273.

Okazaki, T., R. M. Bell, and Y. A. Hannun. 1989. Sphingomyelin turnover induced by vitamin $\mathrm{D}_{3}$ in HL-60 cells. J. Biol. Chem. 264:19076-19080.

Renner, E., G. Schaafsma, and K. J. Scott. 1989. Micronutrients in milk. Pages 1-60 in Micronutrients in Milk and Milk-Based Food Products. E. Renner, ed. Elsevier Applied Science, London, UK.

Rombaut, R., V. Dejonckheere, and K. Dewettinck. 2006. Microfiltration of butter serum upon casein micelle destabilization. J. Dairy Sci. 89:1915-1925

Spence, A. J., R. Jimenez, M. Qian, and L. Goddik. 2009. The influence of temperature and pressure factors in supercritical fluid extraction for optimizing nonpolar lipid extraction from buttermilk powder. J. Dairy Sci. 92:458-468.

Warner, J. N. 1976. Principles of Dairy Processing. John Wiley \& Sons, New York, NY. 